\title{
Erratum to: Prognostic value of regulatory $T$ cells in newly diagnosed chronic myeloid leukemia patients
}

\author{
Asmaa M. Zahran ${ }^{1} \cdot$ Hosny Badrawy $^{1} \cdot$ Abeer Ibrahim $^{1}$
}

Published online: 12 March 2015

(C) Japan Society of Clinical Oncology 2015

\section{Erratum to: Int J Clin Oncol (2014) 19:753-760 \\ DOI 10.1007/s10147-013-0615-9}

In the original publication of the article, Tables 1 and 2 were published incorrectly. The corrected tables should be as below,

Table 1 Characteristics of CML patients (chronic phase) and controls

\begin{tabular}{|c|c|c|c|}
\hline & Patients $(n=45)$ & Controls $(n=40)$ & $P$ value \\
\hline Age & $31 \pm 2.9$ & $29 \pm 1.72$ & \\
\hline Sex (male/female) & $20 / 25$ & $19 / 21$ & \\
\hline Splenomegaly & $40 / 45$ & - & \\
\hline WBCs $\left(10^{9} / \mathrm{L}\right)$ & $206.74 \pm 29.04$ & $6.44 \pm 0.43$ & \\
\hline Platelets $\left(10^{9} / \mathrm{L}\right)$ & $391.50 \pm 63.43$ & $231.25 \pm 15.70$ & \\
\hline Hemoglobin $(\mathrm{gm} / \mathrm{dl})$ & $9.33 \pm 0.22$ & $11.83 \pm 0.29$ & \\
\hline BCR.ABL & $0.081 \pm 0.08$ & - & \\
\hline Blast & $6.35 \pm 0.93$ & - & \\
\hline Basophils & $2.85 \pm 0.49$ & - & \\
\hline BM fibrosis (median) & 2 & - & \\
\hline
\end{tabular}

The online version of the original article can be found under doi:10.1007/s10147-013-0615-9.

Hosny Badrawy

badrawyh@yahoo.com

1 South Egypt Cancer Institute, Assiut University,

EL-Mesak Street, Assiut, Egypt 
Table 2 Regulatory T cells in CML patients (chronic phase) and controls

\begin{tabular}{|c|c|c|c|}
\hline Percentage $(\%)$ & Patients (45) & Control (40) & $P$ value \\
\hline Lymphocytes & $27.30 \pm 1.55$ & $54.15 \pm 1.50$ & 0.000 \\
\hline $\mathrm{CD}^{+}$ & $35.95 \pm 2.56$ & $40.76 \pm 2.55$ & 0.218 \\
\hline $\mathrm{CD} 25^{+} /$total lymphocytes & $6.55 \pm 0.14$ & $6.33 \pm 0.17$ & 0.978 \\
\hline $\mathrm{CD} 4^{+} \mathrm{CD} 25^{1} / \mathrm{CD} 4^{+}$ & $18.10 \pm 0.55$ & $17.61 \pm 0.61$ & 0.569 \\
\hline $\mathrm{CD} 4{ }^{+} \mathrm{CD} 25^{+ \text {Intermediate }+} /$ total lymphocytes & $4.18 \pm 0.09$ & $4.45 \pm 0.12$ & 0.194 \\
\hline $\mathrm{CD} 4^{+} \mathrm{CD} 25^{\text {Intermediate }} / \mathrm{CD} 4^{+}$ & $13.34 \pm 0.61$ & $14.11 \pm 0.37$ & 0.339 \\
\hline $\mathrm{CD} 4^{+} \mathrm{CD} 25^{+ \text {High}} /$ total lymphocytes & $2.37 \pm 0.14$ & $1.88 \pm 0.09$ & 0.012 \\
\hline $\mathrm{CD} 4^{+} \mathrm{CD} 25^{+ \text {High }} / \mathrm{CD} 4^{+}$ & $5.10 \pm 0.33$ & $3.54 \pm 0.18$ & 0.003 \\
\hline $\mathrm{CD}^{+}{ }^{+} \mathrm{CD} 25^{+ \text {High }} \mathrm{FoxP}^{+} /$total lymphocytes & $1.19 \pm 0.12$ & $0.89 \pm 0.06$ & 0.039 \\
\hline $\mathrm{CD}^{+}{ }^{+} \mathrm{CD} 25^{+ \text {High }} \mathrm{FoxP}^{+} / \mathrm{CD} 4^{+}$ & $1.85 \pm 0.13$ & $0.75 \pm 0.11$ & 0.000 \\
\hline $\begin{array}{l}\text { MFI of Foxp } 3^{+} \text {expression in } \\
\text { CD } 4^{+} \mathrm{CD} 25^{+ \text {High }}\end{array}$ & $98.47 \pm 5.58$ & $85.75 \pm 1.29$ & 0.017 \\
\hline
\end{tabular}

